\title{
Ancient Greek and Greco-Roman Methods in Modern Surgical Treatment of Cancer
}

\author{
Niki Papavramidou, $\mathrm{PhD}^{1}$, Theodossis Papavramidis, $\mathrm{PhD}^{2}$, and Thespis Demetriou, $\mathrm{PhD}^{3}$ \\ ${ }^{1}$ History of Medicine, School of Medicine, Democritus University of Thrace, Alexandroupolis, Greece; ${ }^{2} 3$ rd Department of \\ Surgery, AHEPA University Hospital, Thessaloniki, Greece; ${ }^{3}$ Department of Anatomy, School of Medicine, Democritus \\ University of Thrace, Alexandroupolis, Greece
}

Cancer appears in medical history as early as $1600 \mathrm{BC}$ in the Edwin Smith papyrus, where the oldest description of the illness exists. However, the origin of the word "cancer" is credited to the Hippocratic physicians, who used the terms karkinos and karkinoma in order to describe tumors. Karkinos was used for any nonhealing swelling or ulcerous formation, even hemorrhoids, whereas karkinoma was reserved for nonhealing "cancer." ${ }^{1}$ The physicians of antiquity generally used remedies and plasters for local treatment of tumors, as well as cauterization, which was used even by the Hippocratic physicians for treatment of cancer of the pharynx. Nonetheless, in this Editorial, an attempt is made to describe ancient surgical methods that include excision of the tumor and to correlate them with modern medical practice, providing possible explanations for the surgical choices made by ancient authors. Such references were traced in the texts of the Hippocratic physicians, of Archigenes of Apamea, of Galen, of Leonides of Alexandria, and of Paulus Aegineta, ranging from the $5^{\text {th }}$ century $\mathrm{BC}$ to the $7^{\text {th }}$ century AD.

\section{HIPPOCRATIC PHYSICIANS (AFTER THE $4^{\text {TH }}$ CENTURY BC)}

The Hippocratic physicians initiated the discussion on the treatment of cancer and suggested that the most difficult cancers to treat were those of the axillae, the flank of the

(C) Society of Surgical Oncology 2010

Published Online: 5 January 2010

N. Papavramidou, $\mathrm{PhD}$

e-mail: papavramidou@hotmail.com body, and the thigh. ${ }^{2}$ Nevertheless, they advised not to treat surgically cancers that had not ulcerated, because they were thought to be incurable and any interference would lead to the death of the patient, while otherwise the patient might live for a long time. ${ }^{3}$ Unfortunately, no detailed description of the Hippocratic surgical technique of treating cancer is provided by existing texts.

\section{ARCHIGENES OF APAMEA $\left(1^{\text {ST }}-2^{\text {ND }}\right.$ CENTURY AD)}

Many centuries later, Archigenes of Apamea, a Roman medical author and practitioner, used surgical operation for excision of a cancerous growth. His method, which is known through the writings of Oribasius ( $4^{\text {th }}$ century AD), is described in detail. First, he notes that any part of the human body should be removed surgically when affected by sepsis or by certain types of carcinoma, because these parts have already lost their natural connection to the body. Then, he stresses the importance of early diagnosis, because at such a stage, the carcinoma may be healed with the aid of medicaments, avoiding surgery. If, nevertheless, cancer is diagnosed in an advanced stage, excision of the growth is absolutely necessary, although only if the patient is strong and has the power to cope with the operation. Before excising the tumor, the vessels existing in the area need to be tied, or better the circulation of the blood needs to be intercepted with the aid of a ligature. He notes that, in some people, the whole tumor must be "surrounded" with a ligature. Then, effusion of very cold water is prescribed and sometimes the application of a cup. The appropriate instrument for the incision is one proportionate to the affected area. The patient should be laid down in such a position that the instrument can easily make a circular incision without facing any obstacles. After the incision is 
performed, any nerves should be moved away from the perimeter of the wound; the tumor should be completely excised, making sure that the surgeon has scrapped off any membranes that might have been attached to the growth. If hemorrhage occurs, the surgeon should cauterize the area and place a piece of cloth around the bleeding part, avoiding touching the nerves. The wound should then be sutured and a cataplasm of leek, bread, salt, and other astringent ingredients should be applied to the wound. Finally, instructions are given for cleaning the area for 2-3 days with agents that protect against inflammation and promote healing. ${ }^{4}$

\section{GALEN (2 ${ }^{\text {ND }}$ CENTURY AD)}

Almost contemporary to Archigenes, but strongly criticizing him at any given opportunity, Galen, who made a detailed categorization of abnormal growths (he even wrote a treatise named On tumors against nature), believed that cancer may appear in any part of the body, but he had seen it more often occurring in the breasts of women whose menstruation was either abnormal or inexistent. He believed that the cause of this disease is the accumulation of "residues of black bile formed in the liver during hematosis and left aside by the cleaning process taking place in the spleen." 5 These residues are created when the liver is weak, when the diet is of the nature that produces a large amount of thick blood and the spleen is weakly attracting the humor. Such a procedure produces a very thick and mud-like blood that accumulates in the veins. This is how Galen explains the appearance of black veins around the cancerous part that looks like a crab: "as the crab has legs spreading around its body, in the same way are the veins in this illness; they are spread by the abnormal tumor in a shape of crab." ${ }^{5}$ This comparison of the cancerous tumor to a crab is actually the reason for the name of the disease, since karkinos (cancer) means crab in Greek. Additionally, Galen notes that, when such tumors ulcerate, they discharge a dark-reddish and foul-smelling secretion, suggesting that the cause of the illness is black bile. ${ }^{6}$

As for treatment of cancer, Galen suggests that it is only curable at its commencement, otherwise surgery should take place. A round incision should be made around the tumor, so that the entirety of the growth is excised. He advises the surgeon to be extremely careful because there is great danger that hemorrhage will occur and the attempt to restrain it with ligatures may affect neighboring parts with cancer. $\mathrm{He}$ also mentions the use of cauterization for burning of the roots of the tumor, which is a process that may also prove to be dangerous. Finally, he suggests that the physician should try to "thin" the blood first, with the aid of purgative medicaments and then proceed to the operation. ${ }^{5}$

\section{LEONIDES OF ALEXANDRIA (CIRCA $2^{\text {ND }}$ CENTURY AD)}

Leonides of Alexandria is thought to be the first to discriminate between scirrhus and cancer in the breast, and to draw attention to nipple retraction as a sign of malignancy. Leonides ignored the Hippocratic injunction against operating and describes a procedure in which excision is alternated with cautery, which served to remove the cancer and control hemorrhage. ${ }^{1}$ Leonides, whose experience is found in Aëtius of Amida' books, noted that breast cancer appears mainly in women and rarely in men. The tumor is painful because of the intense traction of the nipple. He suggests avoiding operation in case the tumor has taken over the entire breast and adhered to the thorax. However, "if the scirrhous tumor begins at the edge of the breast and spreads in more than half of it, we must try to amputate the breast without cauterization." ${ }^{77}$ The patient should lie on her back and an incision is made on the healthy part of the breast, just above the tumor. Hot irons are used to cauterize the incised tissues until the bleeding stops. Then incision continues, cutting in depth and burning the incised tissues, continuing this procedure for as long as necessary. After the breast has been completely amputated, the physician should again cauterize all tissues. He notes that all cauterizations are applied in order to avoid hemorrhage, except the last one whose aim is to eradicate the illness. ${ }^{7}$ After the excision, the doctor should apply poultices, to promote healing.

\section{PAULUS AEGINETA $\left(7^{\text {TH }}\right.$ CENTURY AD)}

For Paulus Aegineta, cancer is an uneven swelling, rough, unseemly, darkish, and painful. It may appear either without ulceration (what the Hippocratic physicians called "cancer"), which worsens if operated upon, or with ulceration (the Hippocratic "carcinoma"), which occurs due to black bile, spreads with erosion, and appears in all body parts, but especially in the breasts and uterus of women. He believes that operating for uterus cancer is impossible and very dangerous, but in all "external" parts, such as the breasts, surgical treatment must be used. He disagrees with the methods used by other physicians, including cauterization or combination of mastectomy and cauterization of the area, agreeing only with Galen, who uses excision of the tumor and its roots and putrefaction for the discharge of the superfluous black bile. ${ }^{8}$

The study of ancient texts dealing with surgical treatment of cancer provides the reader with numerous conclusions that can be neither verified nor falsified. The Hippocratic physicians suggest that the most difficult cancers to treat are those of the axillae; the "difficulty" may lie either in distinguishing the tumors in the area or in the fact that tangible lymph nodes appear either in 
advanced cancers (especially of the breast) or in lymphomas, namely in situations that in that era and until recently were untreatable or treatable with very high morbidity. The Hippocratic physicians also advised not to treat surgically cancers that had not ulcerated, because they were thought to be incurable and any interference would lead to the death of the patient, while otherwise the patient might live for a long time. This conclusion could have been drawn by the observation of large benign tumors of the breasts, erroneously characterized as cancers, which do not ulcerate and have good prognosis, while any surgical intervention at that time would surely have high morbidity.

Archigenes of Apamea adds to the knowledge of the surgical treatment of cancer, which is advised only in case the patient is strong and has the power to cope with the operation; taking into consideration that there was no anesthesia or antibiotics at the time, this suggestion makes sense, since under these circumstances no surgical operation could be performed. Archigenes also describes various techniques that aim at the disruption of blood supply to and from the tumor. Ligature of the vessels surrounding the growth directly detaches the tumor from the vessels, while in combination with application of cold water, it induces vasoconstriction and, if applied for a long time, thrombosis of the small vessels. Additionally, the application of cups around the tumor possibly aggregates blood in the venal system of the tumor, further inducing stasis and thrombosis of the vascular bed. All these techniques seem to constitute the forerunner of embolization of the vascular supply of the tumors. ${ }^{9}$ Archigenes also suggests the use of instruments proportionate in size to the affected area, in such a way that the instrument may easily make a circular incision without any obstacles. Such a suggestion is reasonable, because the aim was to decrease the duration of the operation, thus decreasing operative pain and possibility of infection. Archigenes' suggestion to move away any nerves from the perimeter of the wound could be reasonable based on avoiding postoperative pain and spread of the tumor to the surrounding tissues by perineural transmission. Finally, both Archigenes and Galen prefer using cauterization rather than ligation, probably in order to increase patient survival, although today we could explain it based on the fact that thermal energy has the additional ability to kill cancer cells, whereas ligation helps control hemorrhage without playing any oncologic role.

Galen believes that the cause of cancer is accumulation of "residues of black bile" created when the liver is weak, when the diet produces a large amount of thick blood and the spleen is weakly attracting the bile. Today, though, it is obvious that all those "causes" are in fact results of advanced carcinomas, which among others, provoke hypotrophy, diminished liver function, and immunodeficiency. Furthermore, Galen suggests, similarly to Archigenes, treating cancer only at its commencement, which is reasonable, bearing in mind that many benign tumors (such as cysts, fibroadenomas, lipomas, etc.) appear as small growths that were erroneously considered to be cancers. If therefore only such kinds of growths were operated upon, the prognosis was of course promising and the operation was considered as a successful one against "cancer." Another important point in the Galenic texts is the advice he gives regarding ligation during operation, in fear of causing "affection of the neighboring parts by cancer." Actually, poor surgical technique may indeed cause implantation of cancer cells to neighboring tissues, as in cases of imperfect resection. Moreover, he mentions the use of cauterization for the "burning of the roots of the tumor"; in advanced carcinoma of the breast, it was probably impossible at that time to radically excise the tumor or infiltrated neighboring structures (notably underlying muscles or bones). Cauterizing these parts possibly ameliorated prognosis through thermal destruction of the cells, which strongly resembles thermoablation, a very innovative treatment for cure of breast cancer. ${ }^{10}$

Taking into consideration the possible explanations provided in the ancient references to surgical treatment of cancer, one can only admire ancient medical practice. Even if most of the explanations were found in modern years, ancient physicians managed to use surgery with skills acquired through observation and experimentation in animals. Poor postoperative results taught the ancient physicians what they were able to do and what not, blaming though the nature of the tumor for any unfortunate prognosis.

\section{REFERENCES}

1. Weiss L. Early concepts of cancer. Cancer Metastasis Rev. 2000;19:205-17.

2. Hippocrate. Prorrhétique II. In: Littré E, editor. Oeuvres complètes d'Hippocrate. Vol. 9. Paris: J. B. Baillière; 1861. p. 32.

3. Hippocrate. Aphorismes VI. In: Littré E, editor. Oeuvres complètes d'Hippocrate. Vol. 4. Paris: J. B. Baillière; 1844. p. 572.

4. Daremberg Ch. Oeuvres d'Oribase. Vol. 4. Paris: Imprimerie Nationale; 1862. p. 244.

5. Galen. Ad glauconeum de methodo medendi. In: Kuhn CG, editor. Opera Omnia. Vol. 11. Lipsiae: Car. Cnoblochii; 1826. p. $139-41$.

6. Galen. De atra bile. In: Kuhn CG, editor. Opera omnia. Vol. 5. Leipzig: Fock; 1823. p. 116-8.

7. Zervos S. Gynaekologie des aëtios. Leipzig: Fock; 1901. p. 1-18.

8. Adams F. The seven books of Paulus Aegineta. Vol. 2. London: Sydenham Society; 1844. p. 332.

9. Vogl T, Naguib N, Nour-Eldin A, Eichler K, Zangos S, GruberRouh T. Transarterial chemoembolization (TACE) with mitomycin $\mathrm{C}$ and gemcitabin for liver metastases in breast cancer. Eur Radiol. doi:10.1007/s00330-009-1525-0.

10. van Esser S, Stapper G, van Diest PJ, van den Bosch MA, Klaessens JH, Mali WP, et al. Ultrasound-guided laser-induced thermal therapy for small palpable invasive breast carcinomas: a feasibility study. Ann Surg Oncol. 2009;16(8):2259-63. 